\title{
Mechanical Properties of a Dental Nano-Composite in Moist Media Determined by Nano-Scale Measurement
}

\author{
A. Karimzadeh, M. R. Ayatollahi, H. Asgharzadeh Shirazi
}

\begin{abstract}
The aim of this study was to evaluate the influence of thermocycling on the mechanical properties of a commercial dental nanocomposite by using the nano-indentation experiment. The resin-based nanocomposite contained silica and zirconia nanofillers. Some disk specimens, each with the diameter of $10 \mathrm{~mm}$ and the thickness of $4 \mathrm{~mm}$ were prepared and the specimens were stored at various environmental conditions. Some of the samples were kept in the ambient condition, other samples were stored in distilled water at room temperature and other ones were thermocycled in distilled water for 1000 cycles between $5^{\circ} \mathrm{C}$ and $55^{\circ} \mathrm{C}$. After preparation of samples, the nano-indentation test was applied on the prepared specimens by Triboscope setup. Then the modulus of elasticity and hardness of the test samples were calculated from the Oliver-Pharr's method using the data obtained from nano-indentation test. The present research showed that the samples stored in distilled water without thermocycling exhibited the highest elasticity modulus when compared to the other samples. In addition, the maximum hardness was observed for thermocycled specimens in distilled water.
\end{abstract}

Index Terms-Dental nanocomposite, thermocycling effect, nano-indentation test, hardness, elasticity modulus.

\section{INTRODUCTION}

Dental restorative materials are used in order to restore teeth, biologically, functionally and aesthetically. Amalgam and dental gold alloys have been used for more than 100 years as a dental restorative material in posterior teeth, and have achieved success in clinical matters. The reason is the similarity between the mechanical properties of these materials and the real teeth in various aspects [1], [2]; but the problem is their color which is different from the tooth making them aesthetically unsuitable for restoration of teeth. Therefore, dental composites were introduced as the tooth-colored restorative materials about 40 years ago. Dental composites are complex, tooth-colored filling materials composed of resin and reinforcing fillers that are used in different sizes. Although, there has been much improvement in dental restorative composites, their constitutive monomer systems have changed slightly. On the other hand, in the evolution of composite materials, their fillers changed fundamentally [3], [4] and led to introducing variety of composite restorative materials including: macrofilled composites, microfilled composites, hybrid composites, microhybrid composites and nanocomposites.

Manuscript received May 30, 2013; revised July 25, 2013.

The authors are with the Department of Mechanical Engineering, Iran University of Science and Technology, Tehran, Iran (e-mail: A_karimzade@mecheng.iust.ac.ir, Hadi_shirazi@mecheng.iust.ac.ir).
Researches conducted on dental composites indicate that strength, elasticity modulus, wear resistance, polymerization shrinkage and generally, the physical and mechanical properties of the composite are improved in direct relation to the amount of micro or nano fillers added [5]-[10].

Many efforts have been devoted to studies in the field of relationship between filler particles in composite resins and their properties. The experiment data provided by previous researches suggest that the filler plays an important role in some properties such as elastic modulus [11], polish retention [12]-[14], wear resistance [14], flexural strength [14]-[17], bond strength [18], color stability, translucency, opalescence [19] and fracture toughness [14], [20], [21]. Also, some other studies have shown the effects of filler size [8], [9], [22], [23] and filler shape [11], [20] on mechanical properties of dental composites.

The nanocomposites are relatively new composites consisting of filler particles in nanometric dimensions (between 20 to $75 \mathrm{~nm}$ ) [14]. The main purpose of using fillers with nanometric dimension in these nanocomposites is the improvement in the strength, wear resistance and ability to polish. The materials used to restore teeth must have enough strength to resist again applied forces during chewing and remain strongly on the related part of the teeth.

Patient's oral conditions such as thermal gradient and humidity can have negative effects on the mechanical and physical properties of restorative materials. The most important reason for replacing dental restorative materials are fracture of restorative section and caries [1].

Thermocycling is an experimental process in which thermal conditions are simulated very similar to the real oral conditions such as thermal stresses created in the teeth and in the dental material during the treatment. The thermocycling simulations should be made in vitro and experimental condition just like the clinical conditions. In the thermocycling process, the test samples are embedded in hot and cold distilled water in order to simulate the temperature cycles in specified numbers and preset times. During the thermocycling process, the temperature gradient and the water absorbed by dental materials cause changes in their material properties. As reported in previous researches, thermocycling increases surface damage of composites and the thermal shock created among composite constitutions can produce microcracks [24]-[26]. Therefore, the assessment of the mechanical properties of dental material exposed to thermocycling process is important.

Nano-indentation experiment is a proper method to obtain the mechanical properties of small-sized samples and also surface properties of coatings. To measure the mechanical properties by common mechanical experiments, it is needed 
to make large-scale samples which results in extra test expenses. On the other hand, determining surface or close to surface properties, by using common tests in macro and micro scales is not easily possible.

In this paper the mechanical properties of a specific dental nanocomposite is obtained by nano-indentation experiment. Also the effects of thermocycling process and different storage conditions on the mechanical properties of dental nanocomposite are investigated.

\section{MethodS AND MATERIALS}

In the present work, specimens were prepared from the Filtek Z350 XT (3M ESPE, Germany) nanocomposite. This resin-based nanocomposite contains a specified combination of individual nanoparticles and nanoclusters. Nanoparticles are discrete nonagglomerated and nonaggregated silica and zirconia fillers of $20 \mathrm{~nm}$ and $4-11 \mathrm{~nm}$ in size, respectively. Loose bound agglomerates of nano-sized silica/zirconia form nanocluster fillers. Since the nanocluster filler particles consist of loose bound agglomerates of nano-sized filler particles, the nanomer sized primary particles can be worn away during abrasion. Therefore, in comparison with traditional hybrid composites, the polish retention of cured composite will be increase. The Filtek Z350 nanocomposite consists of both nanoparticles and nanocluster fillers. The nanocluster particles increase filler loading, physical properties and polish retention of the nanocomposite [27].

The resin consists of Bisphenol A diglycidy ether dimethacrylate (bis-GMA), urethane dimethacrylate (UDMA), triethyleneglycol dimethacrylate (TEGDMA), poly (ethylene glycol) dimethacrylates (PEGDMA) and Bisphenol A polyethylene glycol diether dimethacrylate (bis-EMA). For viscous adjustment, TEGDMA is used. Since UDMA and bis-EMA resins have higher molecular weight and, as a result, double bounds per unit of weight, they can affect the measurable viscosity, which will cause less shrinkage, age reduction and also somehow softer resin matrix [27].

Disc-shaped specimens of $10 \mathrm{~mm}$ diameter and $4 \mathrm{~mm}$ thickness were prepared from the Filtek Z350 nanocomposite. According to the manufacturer's instructions, both sides of samples were light cured for 20 seconds until the polymerization was carried out. Dimensional analysis applied to the samples used in the nano-indentation experiment showed that for a homogeneous material, the indentation test results were independent of all dimensions except depth [28], [29].

By comparing the dimensions of the samples used in this work and the indenter dimensions, it could be concluded that all samples used in this study for nano-indentation experiment, were homogeneous.

In order to evaluate the effect of thermocycling and storage conditions on the mechanical properties of dental nanocomposites, specimens prepared of nanocomposites were divided into three groups. One group of specimens were kept in vitro at room temperature (at $24^{\circ} \mathrm{C}$ ) and the next batch of specimens were stored at the distilled water, and the other specimens were thermocycled in distilled water for 1000 cycles between $5^{\circ} \mathrm{C}$ and $55^{\circ} \mathrm{C}$. As suggested by Gale and
Darvell, a total number of 1000 cycles of thermocycling between $5^{\circ} \mathrm{C}$ and $55^{\circ} \mathrm{C}$ was applied on the samples kept in distilled water with a stopping time of 50 seconds in each of hot and cold environments [30]. According to a study by Brown et al. [31], ten cycles of thermocycling on a sample is equivalent to placing in the oral conditions for a day. Thus, 1000 cycles of thermocycling selected in this research is equivalent to putting the sample inside the patient's mouth for 100 days.

Previous researches demonstrated that high roughness of the sample surface will cause scattering of the hardness and elastic modulus values obtained from nano-indentation test [32]-[34]. To determine the level of acceptable smoothness for the nano-indentation test, ISO 14577 [35], [36] defines a reference based on the maximum indenter depth of the sample $\left(h_{\max }\right)$ which must be greater than 20 times of the mean surface roughness values $\left(R_{a}\right)\left(h_{\max }>20 R_{a}\right)$. In order to obtain a smooth surface for nano-indentation test, all samples were ground with 400 to 2500 grit sandpaper and then polished by diamond paste with meshes of 1 micron and 0.5 microns until the surface was smooth and glossy. The roughness values of samples were measured using atomic force microscopy (AFM) and the roughness analysis was performed on these images by Nanoscope $®$ II software.

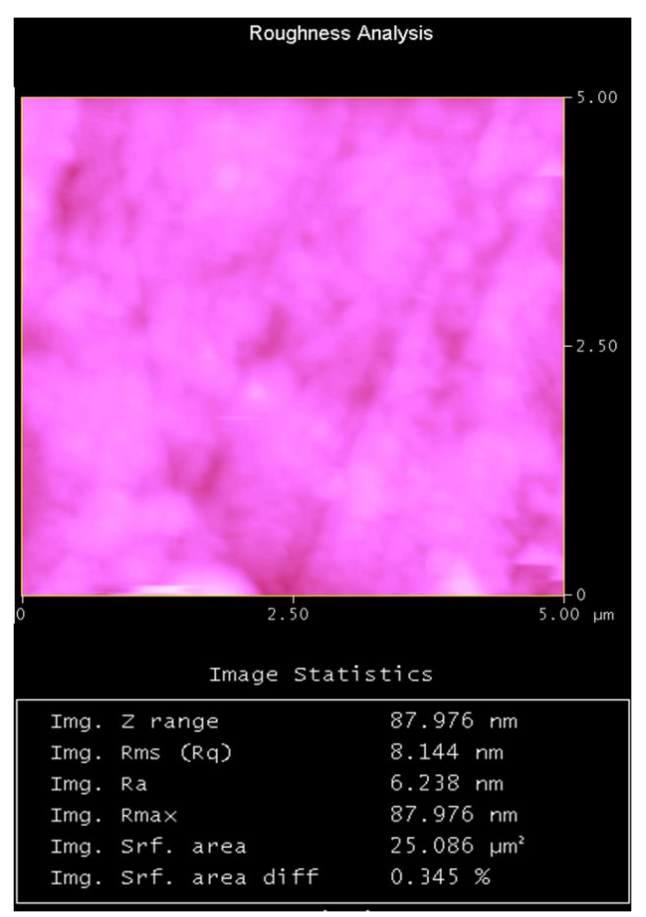

Fig. 1. AFM images from sample surface before nano-indentation testing and results of roughness analysis.

As shown in Fig. 1, the typical mean roughness value of a test sample was $6.238 \mathrm{~nm}$. The mean roughness values of all samples were measured using the described method. The highest value of mean roughness among all samples was $10.798 \mathrm{~nm}$. Therefore, according to the maximum average roughness value of the samples and the criterion introduced by ISO 14577, it can be concluded that if the indenter depth is greater than $215.96 \mathrm{~nm}$, the remained roughness of surface will not be effective on the nano-indentation experiment results. When the smoothness of sample surface reached acceptable level for nano-indentation test, all samples were maintained in ambient temperature (at $24^{\circ} \mathrm{C}$ ) for one hour 
before performing the nano-indentation experiment.

\section{EXPERIMENT}

The nano-indentation test was performed by using Triboscope system (Hysitron Inc., USA) based on International Standards Organization (ISO) 14577 standard and Berkovich indenter. The Berkovich indenter has an average radius of curvature of about $150 \mathrm{~nm}$ and is primarily used for bulk materials and thin films with thicknesses greater than $100 \mathrm{~nm}$. The tip of the testing instrument was calibrated by Oliver-Pharr method (ISO 14577 [37], [38]) and the same method was utilized for analyzing the experimental data. The nano-indentation test uses an established method in which an indenter tip is pressed into specific sites of the material to be tested by applying an increasing normal load. When the penetration depth of the indenter tip achieves a pre-set maximum value, the normal load is reduced until partial or complete relaxation occurs. In this study, an indentation load of $750 \mu \mathrm{N}$ with constant rate of $15 \mu \mathrm{N} \cdot \mathrm{s}^{-1}$ was applied. Previous studies [39], [40] illustrate that the penetration depth of the indenter affects the measured mechanical properties of materials and in most cases, after a depth of $200 \mathrm{~nm}$ the measured properties became almost stable. Indeed, the indentation depth should be deep enough to minimize the surface effect. Meanwhile, the indentation depth should also be less than $10 \%$ of the film thickness when the sample is mounted on a hard substance; otherwise the obtained value is usually larger than the amount it should be, due to the effect of the support [41]. Therefore, the maximum indentation depth in our experiments was limited to $250 \mathrm{~nm}$. The Oliver and Pharr method is dependent of the unloading segment of the load-displacement curve and assumes that only the elastic displacements are recovered. However, with this assumption, an error occurs in determination of the mechanical properties of polymers due to their time and rate dependent behavior. Therefore, in order to eliminate the error in viscous materials, it is common to hold the indenter at the maximum load for a period of time [42], [43]. In the current study, a holding time of $10 \mathrm{~s}$ was selected to minimize the likely error due to the time dependent behavior of the material. According to the explained method, at least five indentations on the randomly selected sites of the samples were performed at a temperature of $24^{\circ} \mathrm{C}$. The AFM images were used for data analysis, before and after the indentations.

\section{RESULTS}

\section{A. Modulus of Elasticity}

Based on the continuous load-displacement data obtained from a complete cycle of loading and unloading during the nano indentation test and by using the Oliver- Pharr method, the effective modulus of elasticity is measured. A sample load-displacement curve measured from the nano-indentation test is shown in Fig. 2. Elasticity modulus of samples can be calculated by using the following equation [38]:

$$
\frac{1}{E_{\text {eff }}}=\frac{1-v^{2}}{E}-\frac{1-v_{i}^{2}}{E_{i}}
$$

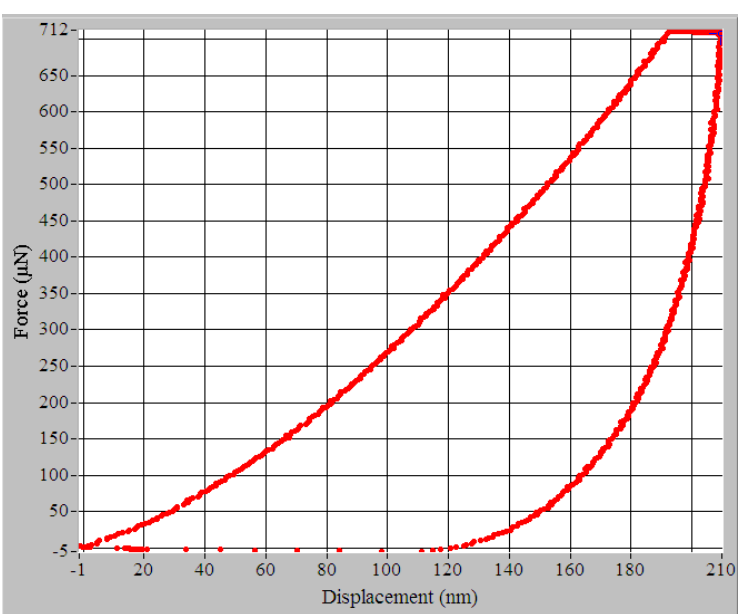

Fig. 2. Load-displacement curve for nanocomposite stored in ambient condition.

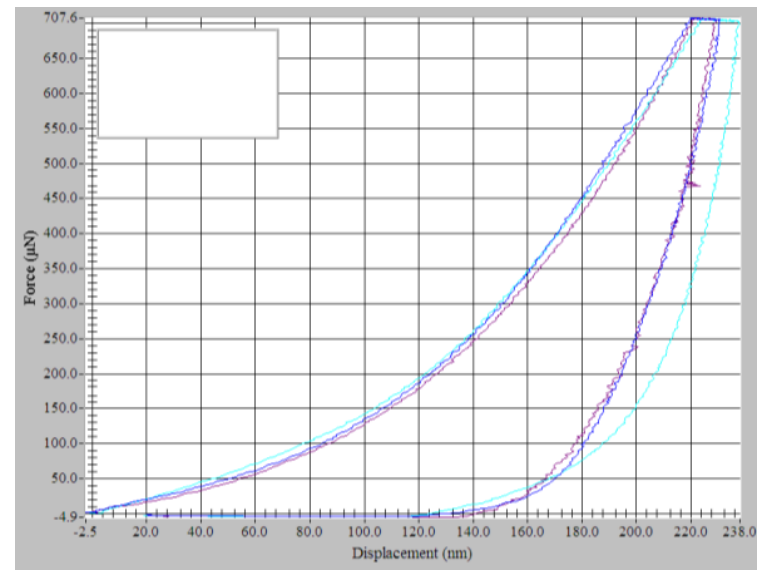

Fig. 3. Repeatability of Load-displacement curves obtained from the nano-indentation test.

where $E$ and $v$ are the elasticity modulus and Poisson's ratio of samples, $E_{i}$ and $v_{i}$ are elasticity modulus and Poisson's ratio of the indenter tip, respectively, and $E_{\text {eff }}$ is the effective elasticity modulus of the material obtained from the nano-indentation test. The AFM images of all indentation tests were studied and the elasticity moduli of all samples were calculated by using Eq. (1) and considering $v=0.31$ [44], $v_{i}=0.07$ and $E_{i}=1140 \mathrm{GPa}$. The values used for $v_{i}$ and $E_{i}$ are based on the technical data available from the related Triboscope system. It is noteworthy that no radial crack around the indentation hole was observed. Cracking around the hole will cause modulus and hardness results measured from nano-indentation tests which will not be reliable, because in this case, a large fraction of the force applied to the indenter is consumed for the formation and growth of cracks instead of material deformation [38]. As mentioned earlier, the hardness and elastic modulus of the specimens were calculated without observing any cracks around the indentation hole. The mean modulus value obtained from the samples is given in Table I. It should be noted that the assessment of force-displacement curve achieved from nano-indentation tests for every sample, represents good repeatability for nanocomposite samples used in this experiment. (Fig. 3)

\section{B. Hardness}

Material hardness is defined as the resistance of material against surface deformation caused by external load. This 
mechanical property can be calculated via dividing the normal load by the projected area of the surface on which it is imposed. The hardness or the normal hardness $\left(H_{n}\right)$ can be calculated in the nano-indentation test from [45]:

$$
H_{n}=\frac{F_{n}^{\prime}}{A}
$$

where $F_{n}^{\prime}$ and A are the maximum load for a given indentation and the projected area of the contact surface between the specimen and the indenter, respectively. In this study, in order to calculate $F_{n}^{\prime}$ and $A$ in Eq. (2), the load-displacement curve obtained from the nano-indentation test and also the Oliver-Pharr method was utilized [38]. The mean hardness value measured from the samples is given in Table I.

TABLE I: VALUES OF ElASTICITY MODULUS AND HARDNESS MEASURED FROM NANO-INDENTATION TESTS

\begin{tabular}{lcc}
\hline Specimen & $\begin{array}{c}\text { Modulus of } \\
\text { elasticity }(\mathrm{GPa})\end{array}$ & $\begin{array}{c}\text { Hardness } \\
(\mathrm{GPa})\end{array}$ \\
\hline $\begin{array}{l}\text { Nanocomposite stored in } \\
\text { ambient condition }\end{array}$ & $10.99 \pm 0.41$ & $0.38 \pm 0.01$ \\
$\begin{array}{l}\text { Nanocomposite stored in } \\
\text { distilled water }\end{array}$ & $15.07 \pm 0.91$ & $0.47 \pm 0.05$ \\
$\begin{array}{l}\text { Thermocycled } \\
\text { nanocomposite in distilled } \\
\text { water }\end{array}$ & $12.07 \pm 0.15$ & $0.61 \pm 0.01$ \\
\hline \hline
\end{tabular}

\section{DISCUSSION}

The results obtained from nano-indentation experiments indicated that the samples stored in distilled water without thermocycling exhibited the highest elasticity modulus compared to other samples. Moreover, the maximum hardness was observed for specimens which were thermocycled in the distilled water. Table I, shows the mean value of the elasticity modulus and hardness of all samples.

It seems that two factors can have influence on mechanical properties of samples exposed to thermocycling process or keeping in distilled water. These two factors respectively are:

1) The effect of humidity on nanocomposite structure.

2) Thermal stresses generated due to thermal gradient in thermocycling process among structural constitutions of the nanocomposite.

The negative influence of water on composites can be explained by two different mechanisms. First mechanism is the role of water molecules in changing the material behavior from elastic state to plastic state which will increase the matrix volume of the nanocomposite. According to this mechanism the stiffness of the material decreases. The second mechanism is the dissolution of composite components in the water.

Previous studies have shown that maintaining the restorative composites and nanocomposites in humid environment have different influences on their mechanical properties including elasticity modulus, depending on temperature and time of storing in water. In some of previous investigations [46], [47], storing the dental composite samples in water for a definite time and specified temperature have led to increase in the elasticity modulus, whereas in others [48] decreased the elasticity modulus. Whereas in some reported cases [49], [50] storing the dental composites in humid ambient have had no impact on elasticity modulus.

A review of the results obtained in this research and in the previous studies [46]-[50] demonstrates that the influence of water on the mechanical properties of dental nanocomposite does not follow a specific law and depends on material type and storage conditions.

Based on the results obtained in this paper, it can be concluded that fillers existing in Filtek Z350 nanocomposite have major influences in the elasticity modulus and hardness values; because even softening of nanocomposite matrix due to water penetration had no effect on the decrease on the stiffness and hardness of the nanocomposite. However, one of the suggested effects of nanocomposite can be the higher water uptake and resultant degradation of resin-matrix interface due to the large surface to volume ratio in the nanoparticles [51].

As mentioned before, creation of thermal stresses in the nanocomposite components generated by thermocycling process is another factor which influences the mechanical properties of samples. The elasticity and hardness values obtained from this study indicate that thermal stress can increase the stiffness and hardness of the nanocomposite. Some previous studies indicate that water sorption, solubility and diffusion coefficients increase due to rise of temperature [52]. Janda et al. [50] illustrated that thermocycling in water ambient can have various effects on the flexural modulus of restorative composites. They indicated that thermocycling in some restorative components lead to reduction of flexural modulus and in some others have no influence on the flexural modulus. Tirado et al. [53] indicated that thermocycling has negative effects on the hardness of some dental composites. It should be mentioned that none of the pervious researches have pointed to thermocycling effect on restorative nanocomposite and according to the present results it can be said that 1000 cycles of thermocycling which is equivalent to 100 days of remaining restoration in mouth [30] increase the elasticity modulus and hardness of the dental nanocomposite.

The elasticity modulus investigated in this study before and after thermocycling is very close to the dentine elasticity modulus (8.7-11.2 GPa) [54]. This is clinically important, because if the restorative elasticity modulus is lower than the elasticity modulus of tooth, the restorative material deforms more than its working conditions in dental substrate against applied stresses. This may lead to damage in the dental substrate around the restorative material or to its separation from the tooth surface.

\section{CONCLUSION}

In this paper elasticity module and hardness was measured for a specific type of nanocomposite using nano-indentation experiment. The effects of two maintenance conditions and 1000 cycles of thermocycling in distilled water on the nanocomposite were studied. The results indicate that:

1) The elasticity modulus of Filtek $Z 350$ nanocomposite is in the range of dentine elasticity modulus. 
2) The samples stored in distilled water without thermocycling exhibited the highest elasticity modulus compared to other samples. Increase in elasticity modulus due to thermocycling process or storing in distilled water is in a way that the nanocomposite still remains in the range of dentine elasticity modulus.

3) The maximum hardness was observed for the samples which were exposed to thermocycling process in distilled water. Therefore, it can be concluded that thermocycling leads to increased hardness of the Filtek Z350 nanocomposite.

\section{REFERENCES}

[1] H. Forss and E. Widström, "Reasons for restorative therapy and the longevity of restorations in adults," Acta Odontologica, vol. 62, pp. 82-86, April 2004.

[2] I. Mifir, A. Jokstad, and V. Qvist, "Longevity of posterior restorations," International Dental Journal, vol. 40, pp. 11-17, January 1990.

[3] A. Peutzfeldt, "Resin composites in dentistry: the monomer systems," European Journal of Oral Sciences, vol. 105, pp. 97-116, April 1997.

[4] R. Walker and J. Burgess, "Comparing resin-based composites," Compendium of Continuing Education in Dentistry, vol. 25, pp. 424-435, July 2004.

[5] J. Ferracane, "Current trends in dental composites," Critical Reviews in Oral Biology \& Medicine, vol. 6, pp. 302-318, February 1995.

[6] K. H. Chung and E. Greener, "Correlation between degree of conversion, filler concentration and mechanical properties of posterior composite resins," Journal of Oral Rehabilitation, vol. 17, pp. 487-494, September 1990.

[7] K.-H. Kim, J. L. Ong, and O. Okuno, "The effect of filler loading and morphology on the mechanical properties of contemporary composites," The Journal of Prosthetic Dentistry, vol. 87, pp. 642-649, June 2002

[8] Y. Li, M. Swartz, R. Phillips, B. Moore, and T. Roberts, "Materials science effect of filler content and size on properties of composites," Journal of Dental Research, vol. 64, pp. 1396-1403, December 1985.

[9] B. Venhoven, A. D. Gee, A. Werner, and C. Davidson, "Influence of filler parameters on the mechanical coherence of dental restorative resin composites," Biomaterials, vol. 17, pp. 735-740, April 1996.

[10] X. Zhao, "The polymerization shrinkage of light cure composite resin," Chinese Journal of Stomatology, vol. 26, pp. 167, May 1991.

[11] S. Beun, T. Glorieux, J. Devaux, J. Vreven, and G. Leloup, "Characterization of nanofilled compared to universal and microfilled composites," Dental Materials, vol. 23, pp. 51-59, January 2007.

[12] H. Lu, L. B. Roeder, and J. M. Powers, "Effect of polishing systems on the surface roughness of microhybrid composites," Journal of Esthetic and Restorative Dentistry, vol. 15, pp. 297-304, September 2003.

[13] A. Yap, K. Lye, and C. Sau, "Surface characteristics of tooth-colored restoratives polished utilizing different polishing systems," Operative Dentistry, vol. 22, pp. 260, November-December 1997.

[14] S. B. Mitra, D. Wu, and B. N. Holmes, "An application of nanotechnology in advanced dental materials," Journal American Dental Association, vol. 134, pp. 1382-1390, October 2003.

[15] S. A. R. Junior, J. L. Ferracane, and Á. D. Bona, "Flexural strength and Weibull analysis of a microhybrid and a nanofill composite evaluated by 3-and 4-point bending tests," Dental Materials, vol. 24, pp. 426-431, March 2008.

[16] N. Ilie and R. Hickel, "Investigations on mechanical behaviour of dental composites," Clinical Oral Investigations, vol. 13, pp. 427-438, December 2009.

[17] Y. Tanimoto, T. Kitagawa, M. Aida, and N. Nishiyama, "Experimental and computational approach for evaluating the mechanical characteristics of dental composite resins with various filler sizes," Acta Biomaterialia, vol. 2, pp. 633-639, November 2006.

[18] T. Hosseinzadeh-Nik, A. Karimzadeh, and M. Ayatollahi, "Bond strength of a nano-composite used for bonding ceramic orthodontic brackets," Materials \& Design, vol. 51, pp. 902-906, May 2013.

[19] B. Yu, H.-N. Lim, and Y.-K. Lee, "Influence of nano-and micro-filler proportions on the optical property stability of experimental dental resin composites," Materials \& Design, vol. 31, pp. 4719-4724, December 2010.

[20] A. R. Curtis, W. M. Palin, G. J. Fleming, A. C. Shortall, and P. M. Marquis, "The mechanical properties of nanofilled resin-based composites: characterizing discrete filler particles and agglomerates using a micromanipulation technique," Dental Materials, vol. 25, pp. 180-187, February 2009.

[21] C. Yilmaz and T. Korkmaz, "The reinforcement effect of nano and microfillers on fracture toughness of two provisional resin materials," Materials \& Design, vol. 28, pp. 2063-2070, January 2007.

[22] M. Bindu, B. K. Satapathy, H. S. Jaggi, and A. R. Ray, "Size-scale effects of silica on bis-GMA/TEGDMA based nanohybrid dental restorative composites," Composites Part B: Engineering, October 2013.

[23] M. M. Karabela and I. D. Sideridou, "Synthesis and study of properties of dental resin composites with different nanosilica particles size," Dental Materials, vol. 27, pp. 825-835, August 2011.

[24] V. Dhuru and C. Lloyd, "The fracture toughness of repaired composite," Journal of Oral Rehabilitation, vol. 13, pp. 413-421, September 1986

[25] R. Draughn et al. , "In vitro surface degradation of composites by water and thermal cycling," Dental Materials, vol. 2, pp. 193-197, October 1986.

[26] L. Mair, "Surface permeability and degradation of dental composites resulting from oral temperature changes," Dental Materials, vol. 5, pp. 247-255, July 1989.

[27] S. Paul, "Technical product profile Filtek," Center M. Filtek ${ }^{\mathrm{TM}}$ Z350 XT Universal Restorative, USA, 2010.

[28] Y.-T. Cheng and C.-M. Cheng, "Scaling, dimensional analysis, and indentation measurements," Materials Science and Engineering: $R$ : Reports, vol. 44, pp. 91-149, August 2004.

[29] F. M. Borodich, L. M. Keer, and C. S. Korach, “Analytical study of fundamental nanoindentation test relations for indenters of non-ideal shapes," Nanotechnology, vol. 14, pp. 803, May 2003.

[30] M. Gale and B. Darvell, "Thermal cycling procedures for laboratory testing of dental restorations," Journal of Dentistry, vol. 27, pp. 89-99, February 1999.

[31] W. Brown, H. Jacobs, and R. Thompson, "Thermal fatigue in teeth," Journal of Dental Research, vol. 51, pp. 461-467, March 1972.

[32] M. Bobji and S. Biswas, "Deconvolution of hardness from data obtained from nanoindentation of rough surfaces," Journal of Materials Research, vol. 14, pp. 2259-2268, June 1999.

[33] J.-Y. Kim, J.-J. Lee, Y.-H. Lee, J.-I. Jang, and D. Kwon, "Surface roughness effect in instrumented indentation: A simple contact depth model and its verification," Journal of Materials Research, vol. 21, pp. 2975-2978, December 2006.

[34] E. Donnelly, S. P. Baker, A. L. Boskey, and M. C. V. D. Meulen, "Effects of surface roughness and maximum load on the mechanical properties of cancellous bone measured by nanoindentation," Journal of Biomedical Materials Research Part A, vol. 77, pp. 426-435, May 2006.

[35] ISO-14577-1, Part 1: Test Method, Switzerland: Geneva, 2002.

[36] C. Ullner, "Requirement of a robust method for the precise determination of the contact point in the depth sensing hardness test," Measurement, vol. 27, pp. 43-51, January 2000.

[37] ISO-14577-1, Part 2: Verification and calibration of testing machines Part 3: Calibration of reference blocks, Switzerland: Geneva, 2002.

[38] W. C. Oliver and G. M. Pharr, "Measurement of hardness and elastic modulus by instrumented indentation: Advances in understanding and refinements to methodology," Journal of Materials Research, vol. 19, pp. 3-20, January 2004.

[39] Y. Hu, L. Shen, H. Yang, M. Wang, T. Liu, T. Liang et al. "Nanoindentation studies on Nylon 11/clay nanocomposites," Polymer Testing, vol. 25, pp. 492-497, June 2006.

[40] T. Liu, I. Y. Phang, L. Shen, S. Y. Chow, and W.-D. Zhang, "Morphology and mechanical properties of multiwalled carbon nanotubes reinforced nylon-6 composites," Macromolecules, vol. 37, pp. 7214-7222, August 2004

[41] A.-Y. Jee and M. Lee, "Comparative analysis on the nanoindentation of polymers using atomic force microscopy," Polymer Testing, vol. 29. pp. 95-99, February 2010.

[42] T. Chudoba and F. Richter, "Investigation of creep behaviour under load during indentation experiments and its influence on hardness and modulus results," Surface and Coatings Technology, vol. 148, pp. 191-198, December 2001.

[43] A. Ngan, H. Wang, B. Tang, and K. Sze, "Correcting power-law viscoelastic effects in elastic modulus measurement using depth-sensing indentation," International Journal of Solids and Structures, vol. 42, pp. 1831-1846, March 2005.

[44] S. M. Chung, A. U. J. Yap, W. K. Koh, K. T. Tsai, and C. T. Lim, "Measurement of Poisson's ratio of dental composite restorative materials," Biomaterials, vol. 25, pp. 2455-2460, June 2004. 
[45] B. Briscoe, P. Evans, S. Biswas, and S. Sinha, "The hardnesses of poly (methylmethacrylate)," Tribology International, vol. 29, pp. 93-104, February 1996.

[46] S. Gladys, B. V. Meerbeek, M. Braem, P. Lambrechts, and G. Vanherle, "Comparative physico-mechanical characterization of new hybrid restorative materials with conventional glass-ionomer and resin composite restorative materials," Journal of Dental Research, vol. 76 pp. 883-894, April 1997.

[47] J. Sabbagh, J. Vreven, and G. Leloup, "Dynamic and static moduli of elasticity of resin-based materials," Dental Materials, vol. 18, pp. 64-71, January 2002.

[48] D. Papadogiannis, R. Lakes, Y. Papadogiannis, G. Palaghias, and M. Helvatjoglu-Antoniades, "The effect of temperature on the viscoelastic properties of nano-hybrid composites," Dental Materials, vol. 24, pp. 257-266, February 2008

[49] S. Chung, A. Yap, K. Tsai, and F. Yap, "Elastic modulus of resin-based dental restorative materials: A microindentation approach," Journal of Biomedical Materials Research Part B: Applied Biomaterials, vol. 72, pp. 246-253, February 2005.

[50] R. Janda, J.-F. Roulet, M. Latta, and S. Rüttermann, "The effects of thermocycling on the flexural strength and flexural modulus of modern resin-based filling materials," Dental Materials, vol. 22, pp. 1103-1108, December 2006.

[51] A. Curtis, A. Shortall, P. Marquis, and W. Palin, "Water uptake and strength characteristics of a nanofilled resin-based composite," Journal of Dentistry, vol. 36, pp. 186-193, March 2008.

[52] P. Dhanpal, C. Yiu, N. King, F. Tay, and N. Hiraishi, "Effect of temperature on water sorption and solubility of dental adhesive resins," Journal of Dentistry, vol. 37, pp. 122-132, February 2009.

[53] J. I. Medina Tirado, W. W. Nagy, V. B. Dhuru, and A. J. Ziebert, "The effect of thermocycling on the fracture toughness and hardness of core buildup materials," The Journal of Prosthetic Dentistry, vol. 86, pp. 474-480, November 2001.

[54] N. Meredith, M. Sherriff, D. Setchell, and S. Swanson, "Measurement of the microhardness and Young's modulus of human enamel and dentine using an indentation technique," Archives of Oral Biology, vol. 41, pp. 539-545, June 1996.

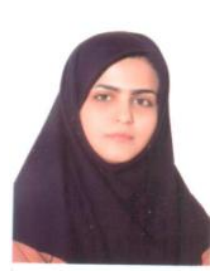

A. Karimzadeh was born in Tehran, Iran on October 15, 1987. She obtained the B.Sc. of Mechanical engineering in Iran University of Science and Technology, Tehran, Iran in 2010; M.Sc. of Mechanical engineering, Iran University of Science and Technology, Tehran in Iran in 2012. She is a Ph.D. student of Mechanical engineering in Iran University of Science and Technology, Tehran, Iran. Her major fields are biomaterials and experimental nano-mechanics.

Her Previous publications are: 1) A. Karimzadeh and M. R. Ayatollahi, "Investigation of mechanical and tribological properties of bone cement by nano-indentation and nano-scratch experiments," Polymer Testing, vol. 31 pp. 828-833, 2012. 2)M. R. Ayatollahi and A. Karimzadeh, "Determination of fracture toughness of bone cement by nano-indentation test," Int J Fract, vol. 175, pp. 193-198, 2012. 3)T. Hosseinzadeh-Nik, A. Karimzadeh, M.R. Ayatollahi, "Bond strength of a nano-composite used for bonding ceramic orthodontic brackets," Materials and Design, vol. 51, pp. 902-906, 2013.

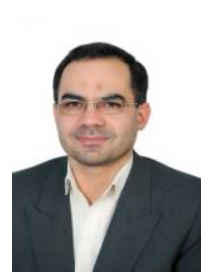

M. R. Ayatollahi is a professor and director of Fatigue and Fracture Research Laboratory in the School of Mechanical Engineering at Iran University of Science and Technology. He has published more than 100 papers in international journals since he received his Ph.D. degree from the University of Bristol in UK in 1999. His main areas of research interests are: fatigue and fracture in engineering materials, experimental solid mechanics, computational and experimental stress analysis.

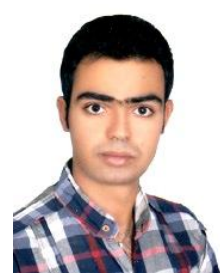

H. Asgharzadeh Shirazi was born in Shiraz, Iran on September 5, 1989. He obtained the B.Sc. of Mechanical engineering, Solids Design from Yasouj University, Yasouj, Iran in 2011, he is M.Sc. student of Mechanical Engineering, Biomechanics, in Iran University of Science and Technology, Tehran, Iran. His Major field is mechanics of biomaterials. 